\title{
Low-Voltage Complex Filters Using Current Feedback Operational Amplifiers
}

\author{
Panagiotis Samiotis and Costas Psychalinos \\ Electronics Laboratory, Physics Department, University of Patras, 26504 Rio Patras, Greece \\ Correspondence should be addressed to Costas Psychalinos; cpsychal@physics.upatras.gr
}

Received 4 April 2013; Accepted 12 May 2013

Academic Editors: H. A. Alzaher and E. Tlelo-Cuautle

Copyright (C) 2013 P. Samiotis and C. Psychalinos. This is an open access article distributed under the Creative Commons Attribution License, which permits unrestricted use, distribution, and reproduction in any medium, provided the original work is properly cited.

\begin{abstract}
A novel complex filter topology realized using current feedback operational amplifiers as active elements is introduced in this paper. Offered benefits are the low-voltage operation capability and the requirement for employing only grounded passive elements. Two application examples are provided, where the frequency behavior of the derived filters fulfills the ZigBee and Bluetooth standards, respectively. Their performance evaluation has been done through simulation results at postlayout level, using MOS transistor models provided by AMS C35B4 CMOS process.
\end{abstract}

\section{Introduction}

Low-IF transceiver architectures suffer from the presence of image signals, caused by the downconversion operation realized by the complex mixing. Unfortunately, due to their symmetrical response around the dc, the conventional real filters do not have the capability for removing the image signals. In order to overcome this problem, a new class of filters denoted by complex filters has been introduced in the literature. Complex filters are constructed from two-path networks, where a pair of signals with equal amplitudes and quadrature phases ( $I$ and $Q$ channels) is applied at their inputs. The concept of complex signal processing is formally described in [1-3].

A significant research effort has been already performed in the literature for designing complex filters suitable for low-IF receivers. The discrete-time topologies in $[4,5]$ have been derived using the switched capacitor and switched current techniques, respectively. Continuous-time filters have been introduced in [6-21]. The topologies in [6, 7] are companding filters realized by utilizing bipolar transistors. The concept of conventional linear continuous-time filtering and MOS transistors has been used in [8-21]. The topologies in [8-14] offer the capability for resistorless realization and this originated from the employment of the operational transconductance Amplifiers (OTAs) [8-12] or current mirrors (CMs) $[13,14]$ as active elements. Second generation current conveyors (CCIIs) in single form $[15,16]$ or fully differential form [17] have been utilized for realizing currentmode complex filters. CCIIs configured as current followers (CFs) and voltage followers (VFs) have been employed in [18], while CCIIs as VFs have been used in [19]. In the topology in [20] operational amplifiers (op-amps) have been used as active elements, while in [21] a number of voltage-mode and current-mode realizations based on transconductance, transresistance, and current amplifiers have been presented and evaluated. Current feedback operational amplifiers (CFOAs) have been used for realizing complex filter functions in [22, 23]. The topology in [22] is a mixed mode circuit and, thus, additional input interfaces are required in order to be voltage mode or current mode. A drawback of the circuit in [23] is the requirement for floating capacitors and resistors.

The design of voltage-mode complex filters with only grounded passive elements and CFOAs is feasible using the building blocks introduced in this paper. An additional attractive characteristic is their potential for low-voltage operation due to the utilization of an appropriate CFOA topology. The paper is organized as follows: the complex 


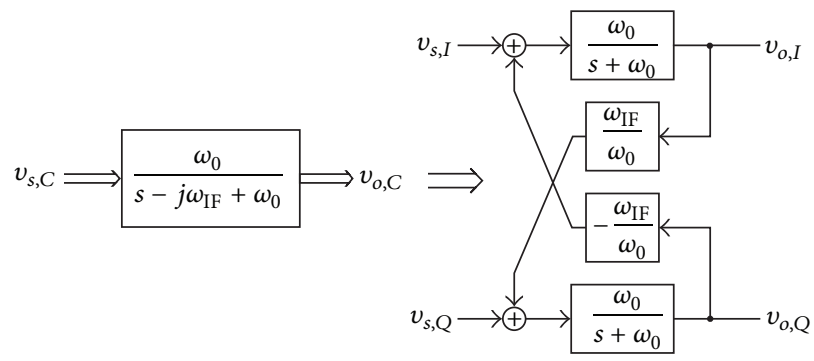

(a)

(b)

FIGURE 1: FBD of complex lossy integrator in (a) condensed and (b) detailed notation.

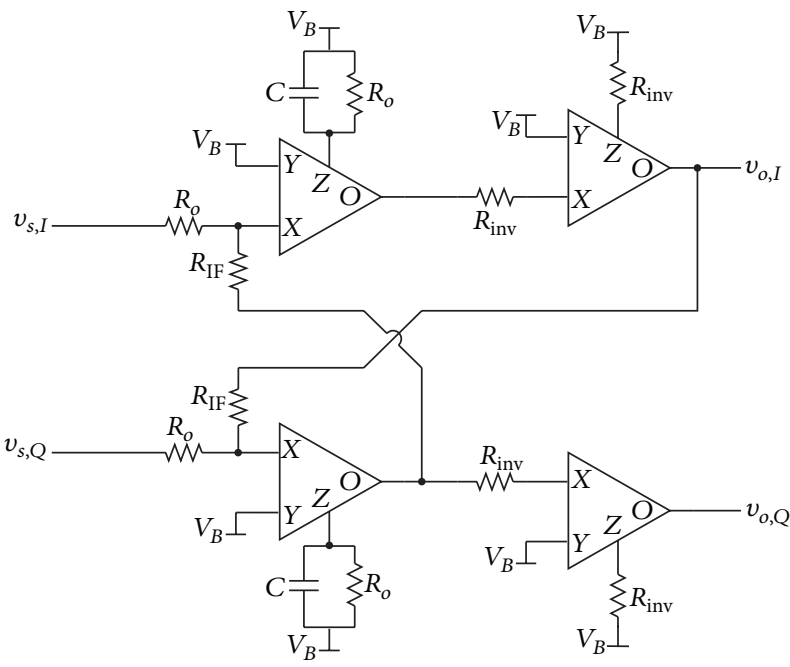

(a)

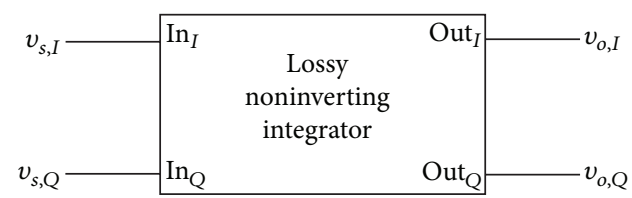

(b)

FIGURE 2: Non-inverting complex lossy integrator (a) realization using CFOAs, (b) associated symbol.

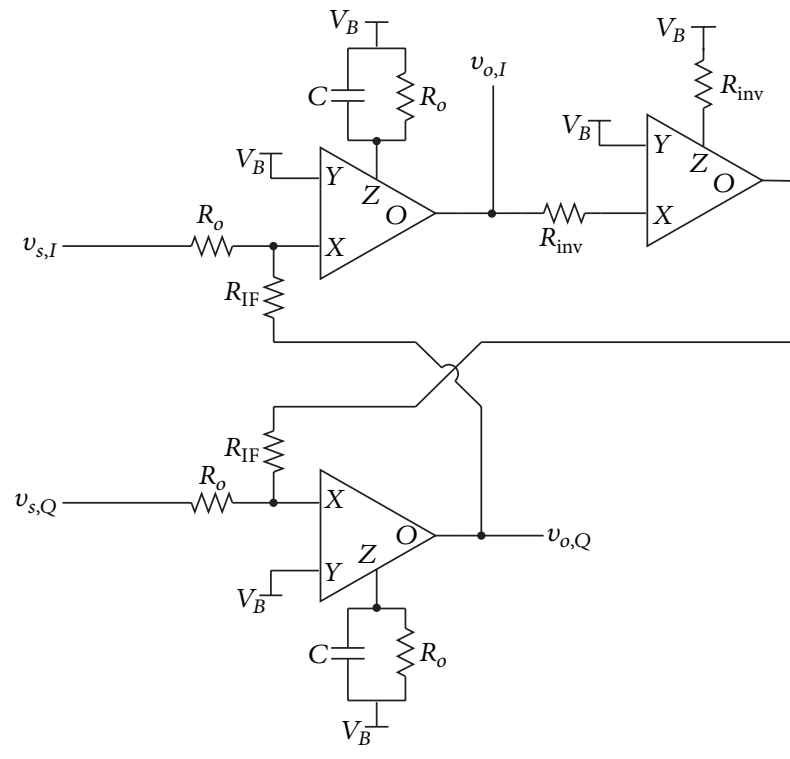

(a)

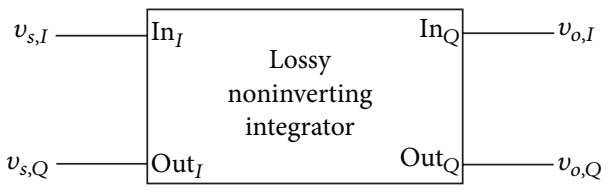

(b)

FIGURE 3: Inverting complex lossy integrator (a) realization using CFOAs, (b) associated symbol. 


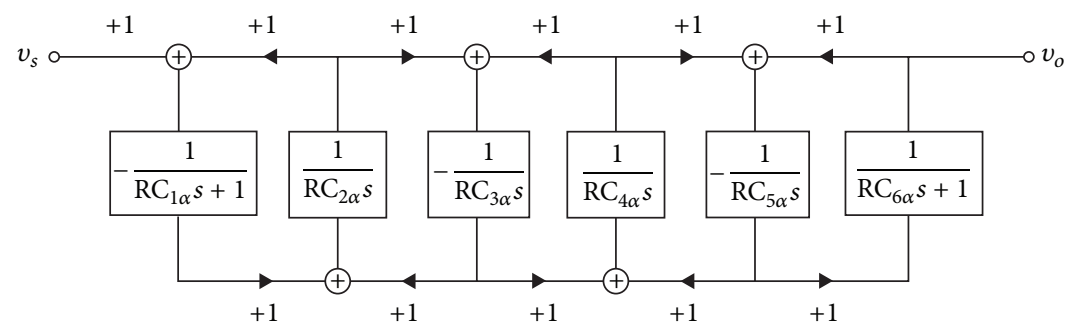

FIGURE 4: FBD of the 6th-order real prototype filter.

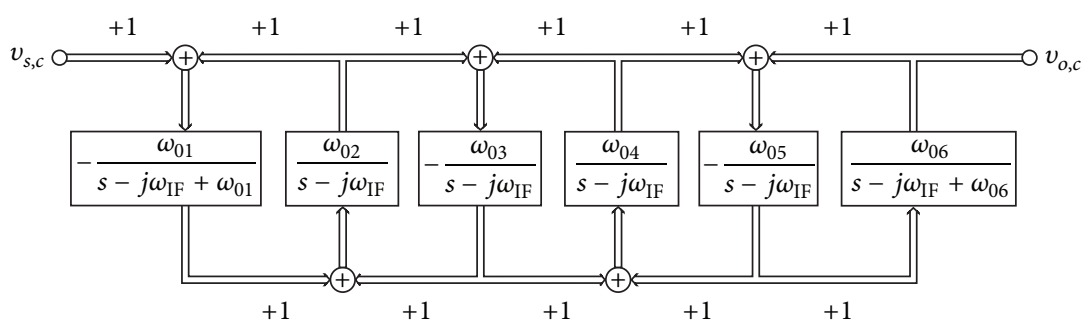

FIgURE 5: FBD of the 12th-order complex filter.

integrators are presented in Section 2, while a 12th-order filter design example is given in Section 3. Post layout simulation results using the Analog Design Environment of Cadence are also presented in Section 3, where it is verified that the proposed filter fulfills the requirements of both ZigBee and Bluetooth standards.

\section{Complex Integrators Using CFOAs}

The transfer function of a complex integrator could be easily derived by performing a frequency shifting (denoted by $\omega_{I F}$ ) of the transfer function of the corresponding real integrator according to the transposition $s \rightarrow s-j \omega_{I F}[24,25]$. Thus, the functional block diagram (FBD) of a lossy complex integrator is given in Figure 1, where variable $v_{c}$ describes a complex voltage according to the definition: $v_{c} \equiv v_{I}+j v_{\mathrm{Q}}$.

The realization of the FBD in Figure 1(a) using CFOAs as active elements is given in Figure 2, where the voltage $V_{B}$ represents a dc voltage source with appropriate value in order the topology to be compatible for operation in a single power supply voltage environment. Using the CFOA terminals' properties it is derived that

$$
\begin{aligned}
& v_{o, I}=\frac{1}{R_{o} C s+1}\left(v_{s, I}-\frac{R_{o}}{R_{I F}} v_{o, Q}\right), \\
& v_{o, Q}=\frac{1}{R_{o} C s+1}\left(v_{s, Q}+\frac{R_{o}}{R_{I F}} v_{o, I}\right) .
\end{aligned}
$$

Using (1), the complex transfer function of the filter is given by (2) as

$$
H_{c}(s) \equiv \frac{v_{o, c}}{v_{s, c}}=\frac{\omega_{o}}{s+\omega_{o}-j \omega_{I F}},
$$

where the cutoff frequency is defined by (3)

$$
\omega_{o}=\frac{1}{R_{o} C},
$$

and the shift frequency by (4)

$$
\omega_{I F}=\omega_{o} \frac{R_{o}}{R_{I F}} .
$$

An inverting lossy integrator is depicted in Figure 3, where is evident the reduced count of active elements. The corresponding noninverting and inverting complex lossless integrators could be derived from those in Figures 2 and 3, by omitting the resistors in parallel connection with capacitors.

Inspecting the topologies in Figures 2 and 3 it is concluded that.

(a) A direct interconnection between intermediate stages of the filter could be performed, instead of using extra interface stages as in [22]. More specifically two CCIIs configured as voltage-to-current $(V / I)$ converters could be used for performing the required input signal conversion, due to the mixed-mode nature of the topologies in [22]. It should be also mentioned that in the case of filters, where the integrationsummation operation is required, four CCIIs must be used in order to construct a complex integrator with summation capability.

(b) Only grounded passive elements are required and this is not the case for the topologies in [23], where floating resistors and capacitors are required. It should be mentioned at this point that the employment of grounded passive elements is a benefit from the implementation point of view. 


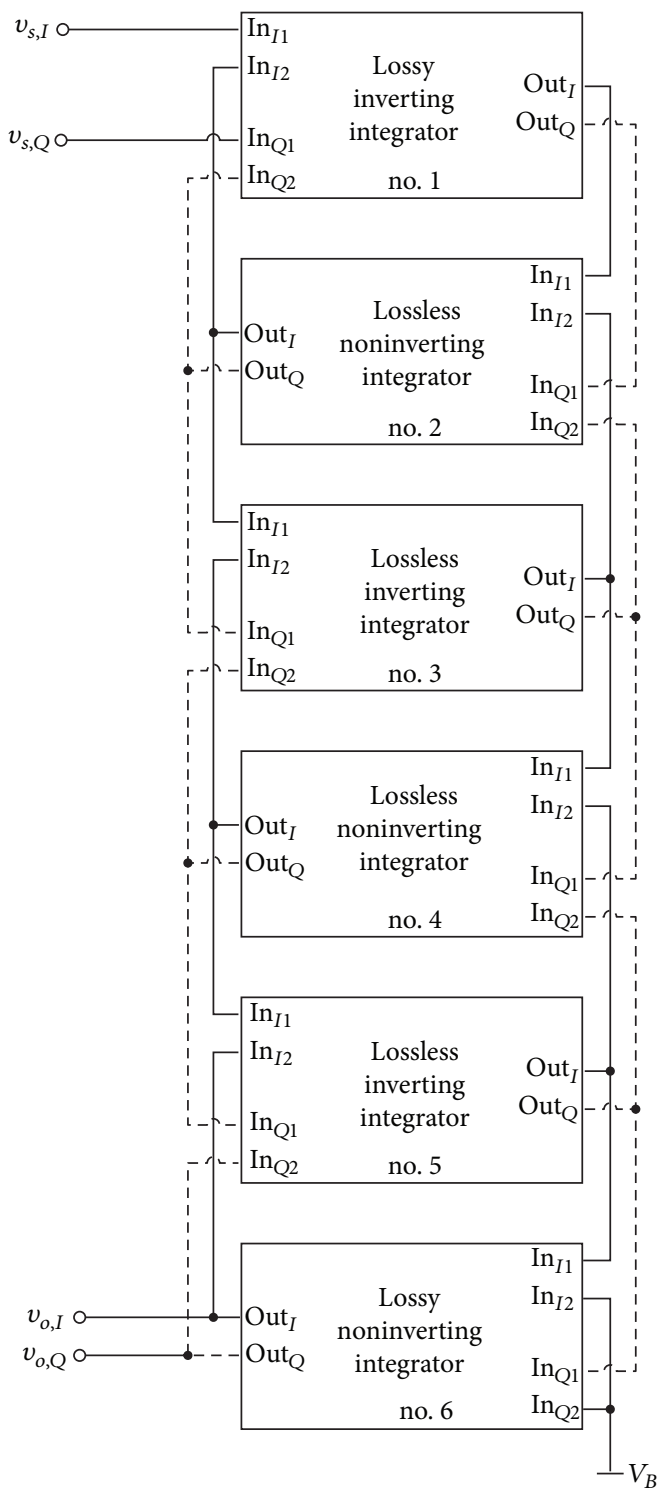

FIGURE 6: Realization of the FBD in Figure 5.

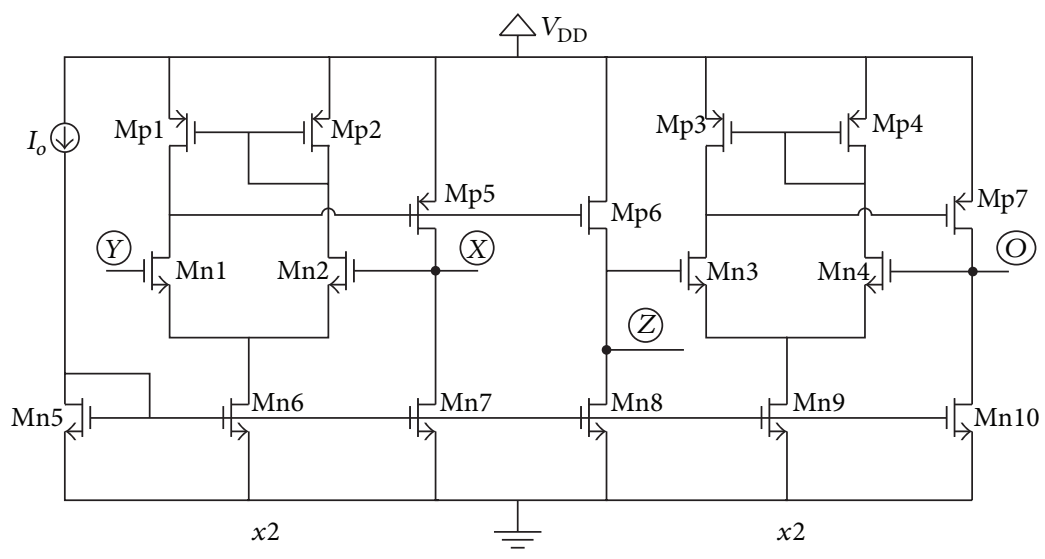

FIGURE 7: CFOA stage employed in simulations. 


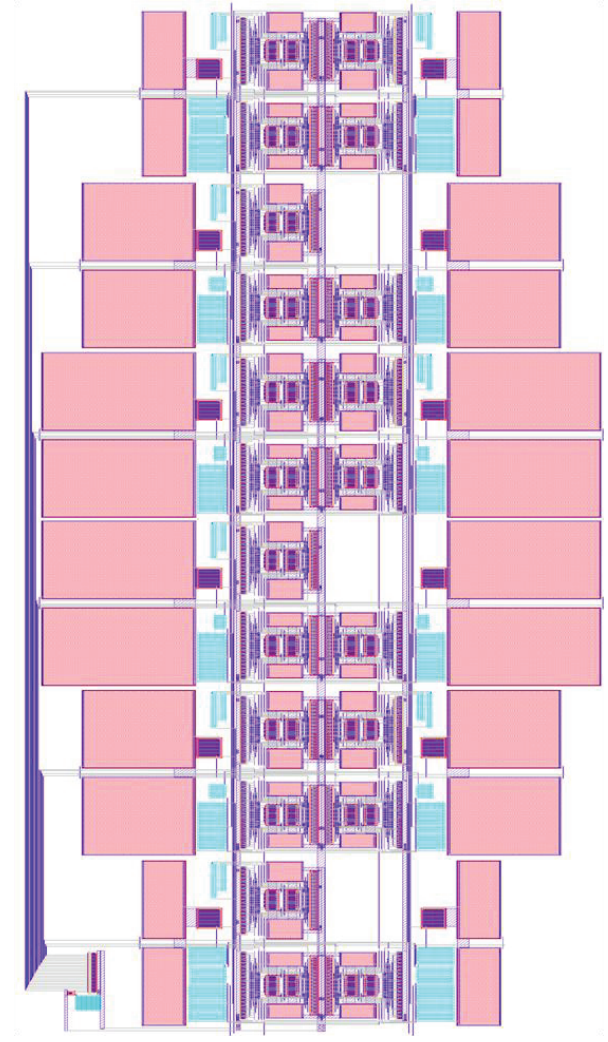

FIgURE 8: Layout design of the filter in Figure 6.

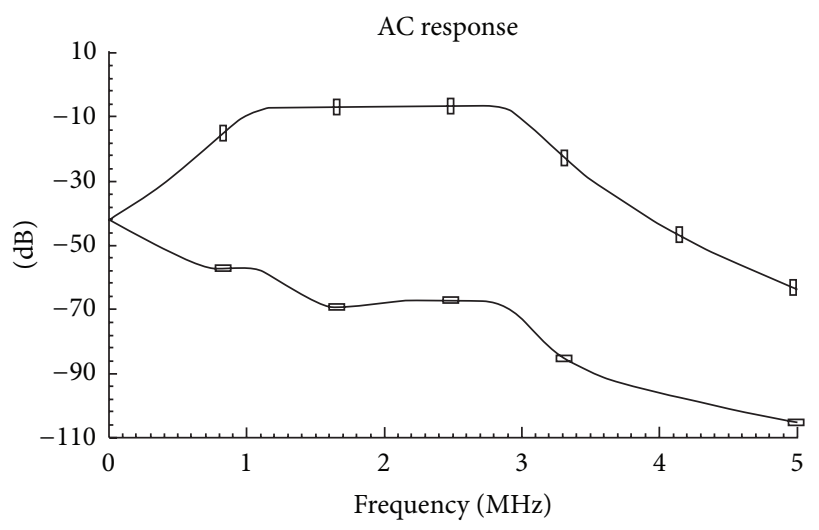

[. Signal responce

$\square$ Image responce

Figure 9: Postlayout simulated frequency responses for ZigBee mode.

\section{Complex Filter Design Example}

A 12th-order complex filter topology which will meet the requirements of ZigBee and Bluetooth standards will be designed. For ZigBee filter an intermediate frequency $\left(\omega_{I F}\right)$ of $2 \mathrm{MHz}$ and a bandwidth of $1 \mathrm{MHz}$ on each side of the center frequency have been considered. Due to the fact that the center frequency and the bandwidth of Bluetooth filter are exactly halved than those in the ZigBee case, a Bluetooth filter

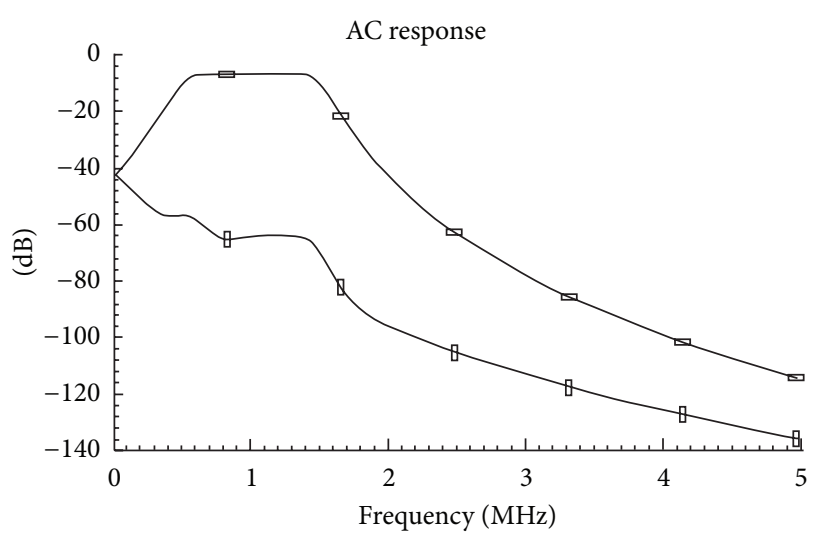

T Signal responce

$\square$ Image responce

Figure 10: Postlayout simulated frequency responses for Bluetooth mode.

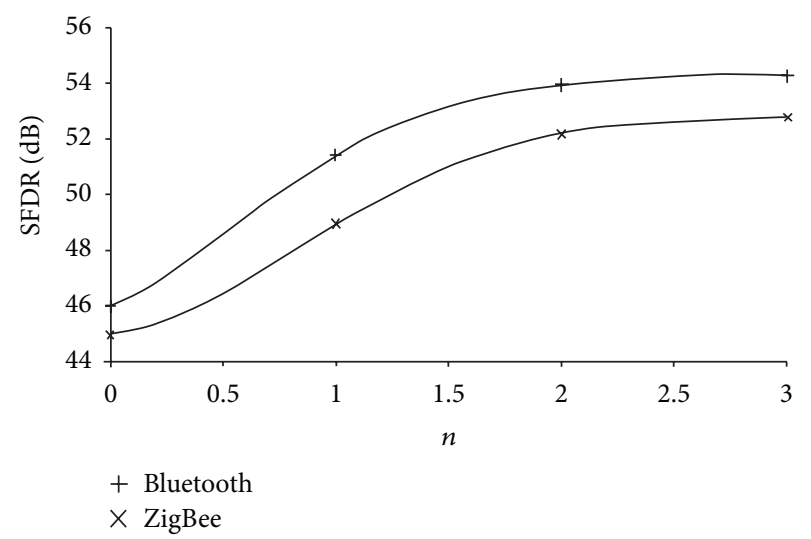

FIGURe 11: Postlayout simulation results of SFDR of the filter at various two-tone input tests.

could be easily realized by doubling the values of integration capacitors.

A 6th-order low-pass Butterworth filter with a cutoff frequency $1 \mathrm{MHz}$ has been chosen as prototype and its FBD is shown in Figure 4. The transposed FBD is depicted in Figure 5, while its realization using CFOAs is presented in Figure 6. Considering an impedance level, $R_{o}=15 \mathrm{k} \Omega$ and $\omega_{I F}=1 \mathrm{MHz}$, the values of passive elements calculated according to (3) and (4) are summarized in Table 1.

The CFOA stage employed for realizing the required complex integrator blocks is given in Figure 7 [26]. To bias current was $I_{0}=10 \mu \mathrm{A}$ and the employed power supply voltage scheme was $V_{\mathrm{DD}}=1.5 \mathrm{~V}$ and $V_{B}=1 \mathrm{~V}$. Considering MOS transistor models provided by AMS C35D4 CMOS process, the aspect ratio of nMOS transistors was $10 \mu \mathrm{m} / 1 \mu \mathrm{m}$, while the corresponding ratio for pMOS transistors was $74 \mu \mathrm{m} / 1 \mu \mathrm{m}$. The layout design of the filter in Figure 6 is demonstrated in Figure 8.

Using the Analog Design Environment of the Cadence software, the obtained postlayout simulation results will be 
TABLE 1: Passive elements values of the filter in Figure 8.

\begin{tabular}{lcc}
\hline Component & ZigBee & Bluetooth \\
\hline$R_{o}$ & $15 \mathrm{k} \Omega$ & $15 \mathrm{k} \Omega$ \\
$R_{\mathrm{inv}}$ & $5 \mathrm{k} \Omega$ & $5 \mathrm{k} \Omega$ \\
$R_{I F 1}=R_{I F 6}$ & $14.9 \mathrm{k} \Omega$ & $14.9 \mathrm{k} \Omega$ \\
$R_{I F 2}=R_{I F 5}$ & $5.36 \mathrm{k} \Omega$ & $5.36 \mathrm{k} \Omega$ \\
$R_{I F 3}=R_{I F 4}$ & $3.92 \mathrm{k} \Omega$ & $3.92 \mathrm{k} \Omega$ \\
$C_{1 a}=C_{6 a}$ & $5.34 \mathrm{pF}$ & $10.67 \mathrm{pF}$ \\
$C_{2 a}=C_{5 a}$ & $14.55 \mathrm{pF}$ & $29.1 \mathrm{pF}$ \\
$C_{3 a}=C_{4 a}$ & $19.9 \mathrm{pF}$ & $39.8 \mathrm{pF}$ \\
\hline
\end{tabular}

TABLE 2: Performance post-layout simulation results of the filter in Figure 8.

\begin{tabular}{|c|c|c|}
\hline Performance factor & ZigBee & Bluetooth \\
\hline Power dissipation & $5.6 \mathrm{~mW}$ & $5.6 \mathrm{~mW}$ \\
\hline Center frequency $\left(f_{o}\right)$ & $1.9 \mathrm{MHz}$ & $920 \mathrm{kHz}$ \\
\hline Bandwidth (BW) & $1.9 \mathrm{MHz}$ & $920 \mathrm{kHz}$ \\
\hline Group delay variation & $0.5 \mu \mathrm{s}$ & $1 \mu \mathrm{s}$ \\
\hline INOISE & $260 \mu \mathrm{V}_{\mathrm{rms}}$ & $260 \mu \mathrm{V}_{\mathrm{rms}}$ \\
\hline $\begin{array}{l}\text { Image rejection ratio } \\
\text { (IRR) }\end{array}$ & $40 \mathrm{~dB}$ & $41 \mathrm{~dB}$ \\
\hline $\begin{array}{l}\text { 1st blocker } \\
\text { Attenuation }\left(f_{o}+\mathrm{BW}\right)\end{array}$ & $37 \mathrm{dBc}$ & $37 \mathrm{dBc}$ \\
\hline $\begin{array}{l}\text { 2nd blocker } \\
\text { Attenuation } \\
\left(f_{o}+2 \mathrm{BW}\right)\end{array}$ & $71.5 \mathrm{dBc}$ & $73.5 \mathrm{dBc}$ \\
\hline $\begin{array}{l}\text { 3rd blocker } \\
\text { Attenuation } \\
\left(f_{o}+3 \mathrm{BW}\right)\end{array}$ & $91 \mathrm{dBc}$ & $94.5 \mathrm{dBc}$ \\
\hline \multirow[t]{2}{*}{ In-Band SFDR } & $44 \mathrm{~dB}$ & $45 \mathrm{~dB}$ \\
\hline & \multicolumn{2}{|c|}{$47.6 \mathrm{~dB} @ 4 \& 6 \mathrm{MHz} 50.2 \mathrm{~dB} @ 2$ \& $3 \mathrm{MHz}$} \\
\hline \multirow[t]{2}{*}{ Out-of-Band SFDR } & \multicolumn{2}{|c|}{$50.4 \mathrm{~dB} @ 6 \& 10 \mathrm{MHz} 52.8 \mathrm{~dB} @ 3 \& 5 \mathrm{MHz}$} \\
\hline & \multicolumn{2}{|c|}{$51.7 \mathrm{~dB} @ 8$ \& $14 \mathrm{MHz} 53.1 \mathrm{~dB} @ 4$ \& $7 \mathrm{MHz}$} \\
\hline
\end{tabular}

presented. The frequency responses of ZigBee and Bluetooth mode of operation are given in Figures 9 and 10, respectively. Concerning the ZigBee mode, the center frequency and the bandwidth were $f_{o}=1.9 \mathrm{MHz}$ and $\mathrm{BW}=1.9 \mathrm{MHz}$, while for Bluetooth the corresponding values were $f_{o}=920 \mathrm{kHz}$ and $\mathrm{BW}=920 \mathrm{kHz}$. The achieved values of attenuation at frequencies $f_{o}+\mathrm{BW}, f_{o}+2 \mathrm{BW}$, and $f_{o}+3 \mathrm{BW}$ were $37 \mathrm{dBc}$, $71.5 \mathrm{dBc}$, and $91 \mathrm{dBc}$ for the Zigbee filter and $37 \mathrm{dBc}, 73.5 \mathrm{dBc}$, and $94.5 \mathrm{dBc}$ for the Bluetooth filter.

Also the achieved image rejection ratio (IRR) was $40 \mathrm{~dB}$ for the ZigBee filter and $41 \mathrm{~dB}$ for the Bluetooth filter. Thus, both filter functions fulfill the selectivity requirements of the corresponding standards. Also, the maximum group delay variation was $0.5 \mu \mathrm{s}$ for ZigBee filter and $1 \mu \mathrm{s}$ for Bluetooth filter.

The linearity of the filter has been evaluated by performing a two-tone test. For this purpose, two input signals located at frequencies $f_{1}=f_{o}+n \times \mathrm{BW}$ and $f_{2}=f_{o}+n \times 2 \mathrm{BW}$ $(n=1,2,3, \ldots)$, where $f_{o}$ is the center frequency and BW is the bandwidth of the filter, have been applied at the input of the filter. Considering the Spurious-Free Dynamic Range $\mathrm{SFDR}=2 / 3\left(\mathrm{IIP}_{3}-\right.$ INOISE $)$, where $\mathrm{IIP}_{3}$ is the input referred 3rd-order intercept point and INOISE is the input referred noise, the obtained plot of SFDR versus the location of the tones is given in Figure 11 for both modes of operation. The achieved values of the in-band SFDR $(n=0)$ was $44 \mathrm{~dB}$ for ZigBee filter and $45 \mathrm{~dB}$ for Bluetooth filter. In order to facilitate the reader, the obtained performance results are summarized in Table 2.

\section{Conclusions}

A complex filter topology realized using CFOAs as active elements is presented in this paper. Attractive benefits are the requirement for only grounded passive elements and the capability for operation in a low-voltage environment. The provided simulation results at postlayout level confirm that the proposed topology could be employed for realizing highperformance analog processing systems.

\section{References}

[1] W. M. Snelgrove and A. S. Sedra, "State-space synthesis of complex analog filters," in Proceedings of the European Conference on Circuit Theory and Design (ECCTD '81), pp. 420-424, 1981.

[2] G. R. Lang and P. O. Brackett, "Complex analogue filters," in Proceedings of the European Conference on Circuit Theory and Design (ECCTD '81), pp. 412-419, 1981.

[3] K. W. Martin, "Complex signal processing is not complex," IEEE Transactions on Circuits and Systems I, vol. 51, no. 9, pp. 18231836, 2004.

[4] K. Suzuki, M. Ugajin, and M. Harada, "A 5th-order switchedcapacitor complex filter for low-IF narrowband wireless receivers," in Proceedings of the IEEE Radio and Wireless Symposium (RWW' '10), pp. 420-423, New Orleans, Lo, USA, January 2010.

[5] A. Worapishet, R. Sitdhikorn, A. Spencer, and J. B. Hughes, "A multirate switched-current filter using class- $\mathrm{AB}$ cascoded memory," IEEE Transactions on Circuits and Systems II, vol. 53, no. 11, pp. 1323-1327, 2006.

[6] N. Y. Voo, M. Teplechuk, and J. I. Sewell, "General synthesis of complex analogue filters," IEE Proceedings G, vol. 152, pp. 7-15, 2005.

[7] C. Psychalinos, "Low-voltage log-domain complex filters," IEEE Transactions on Circuits and Systems I, vol. 55, no. 11, pp. 34043412, 2008.

[8] P. Andreani and S. Mattisson, "On the use of Nauta's transconductor in low-frequency CMOS gm-C bandpass filters," IEEE Journal of Solid-State Circuits, vol. 37, no. 2, pp. 114-124, 2002.

[9] J. B. Hughes, A. Spencer, A. Worapishet, and R. Sitdhikorn, "1 $\mathrm{mW}$ CMOS polyphase channel filter for Bluetooth," IEE Proceedings: Circuits, Devices and Systems, vol. 149, no. 5-6, pp. 348-354, 2002.

[10] A. A. Emira and E. Sánchez-Sinencio, "A pseudo differential complex filter for bluetooth with frequency tuning," IEEE Transactions on Circuits and Systems II, vol. 50, no. 10, pp. 742754, 2003.

[11] B. Guthrie, J. Hughes, T. Sayers, and A. Spencer, "A CMOS gyrator low-IF filter for a dual-mode Bluetooth/ZigBee transceiver," IEEE Journal of Solid-State Circuits, vol. 40, no. 9, pp. 1872-1878, 2005. 
[12] J. Mahattanakul and P. Khumsat, "Structure of complex elliptic Gm-C filters suitable for fully differential implementation," IET Circuits, Devices and Systems, vol. 1, no. 4, pp. 275-282, 2007.

[13] C. Laoudias and C. Psychalinos, "Low-voltage bluetooth /ZigBee complex filter using current mirrors," in Proceedings of the IEEE International Symposium on Circuits and Systems: Nano-Bio Circuit Fabrics and Systems (ISCAS '10), pp. 1268-1271, Paris, France, June 2010.

[14] C. Laoudias and C. Psychalinos, "1.5 V complex filters using current mirrors," IEEE Transactions on Circuits and Systems II, vol. 59, pp. 575-579, 2011.

[15] X. Zhang, X. Ni, M. Iwahashi, and N. Kambayashi, "Realization of universal active complex filter using CCIIs and CFCCIIs," Analog Integrated Circuits and Signal Processing, vol. 20, no. 2, pp. 129-137, 1999.

[16] M. T. Abuelma'atti and S. M. Al-Shahrani, "A new polyphase current-mode filter using programmable-gain current-controlled current-conveyor," WSEAS Transactions on Electronics, vol. 2, no. 4, pp. 138-141, 2005.

[17] E. A. Soliman and S. A. Mahmoud, "New CMOS fully differential current conveyor and its application in realizing sixth order complex filter," in Proceedings of the IEEE International Symposium on Circuits and Systems (ISCAS '09), pp. 57-60, May 2009.

[18] H. A. Alzaher and M. K. Alghamdi, "A CMOS bandpass filter for low-IF Bluetooth receivers," IEEE Transactions on Circuits and Systems I, vol. 53, no. 8, pp. 1636-1647, 2006.

[19] H. Alzaher, M. Al-Ghamdi, and M. Ismail, "CMOS low-power bandpass if filter for Bluetooth," IET Circuits, Devices and Systems, vol. 1, no. 1, pp. 7-12, 2007.

[20] H. Alzaher, "A CMOS highly linear digitally programmable active-RC design approach," IEEE Transactions on Circuits and Systems I, vol. 58, pp. 2636-2646, 2011.

[21] H. Alzaher, N. Tasadduq, and F. Al-Ammari, "Optimal low power complex filters," IEEE Transactions on Circuits and Systems I, vol. 60, pp. 885-895, 2013.

[22] M. T. Abuelma'atti and S. M. Al-Shahrani, "A new polyphase mixed-mode bandpass filter section using current-feedback operational amplifiers," WSEAS Transactions on Electronics, vol. 2, no. 4, pp. 128-131, 2005.

[23] M. Ün, "Implementation of polyphase filter section with CFAs," Frequenz, vol. 58, no. 9-10, pp. 221-224, 2004.

[24] C. Sánchez-López, "Pathological equivalents of fully-differential active devices for symbolic nodal analysis," IEEE Transactions on Circuits and Systems I, vol. 60, pp. 603-615, 2013.

[25] C. Sánchez-López, F. V. Fernández, E. Tlelo-Cuautle, and S. X.D. Tan, "Pathological element-based active device models and their application to symbolic analysis," IEEE Transactions on Circuits and Systems I, vol. 58, pp. 1382-1395, 2011.

[26] G. Raikos and C. Psychalinos, "Low-Voltage current feedback operational amplifiers," Circuits, Systems, and Signal Processing, vol. 28 , no. 3, pp. 377-388, 2009. 

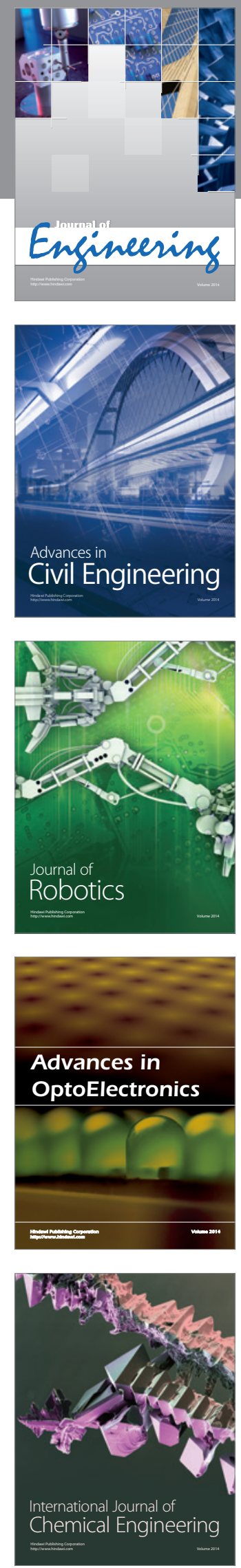

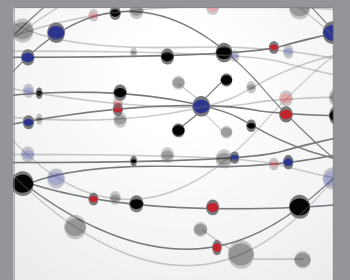

The Scientific World Journal
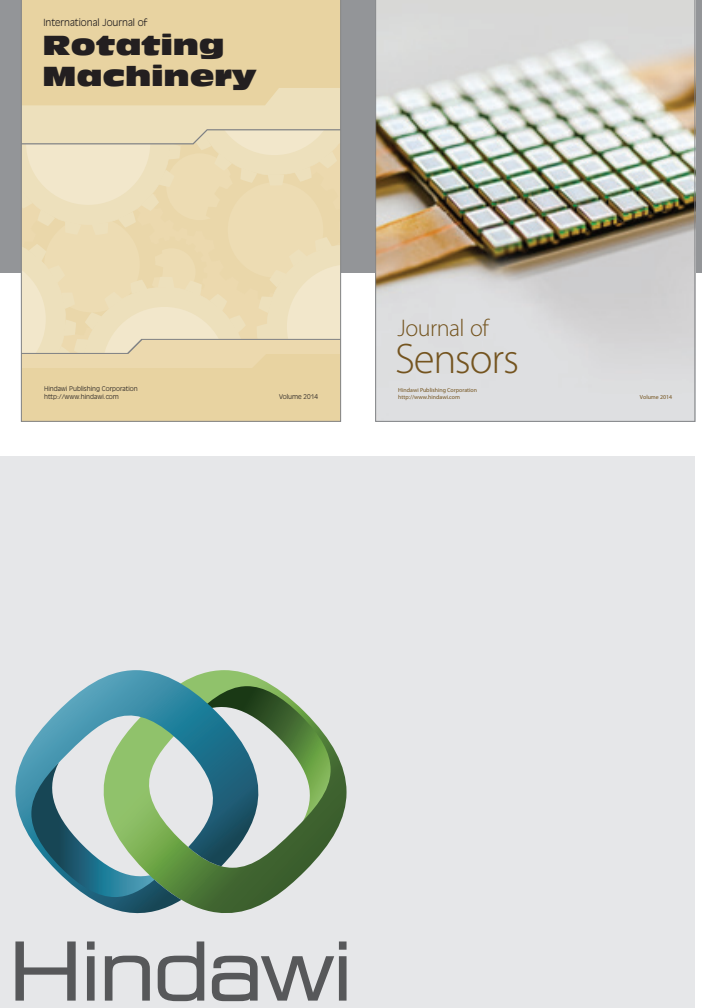

Submit your manuscripts at http://www.hindawi.com
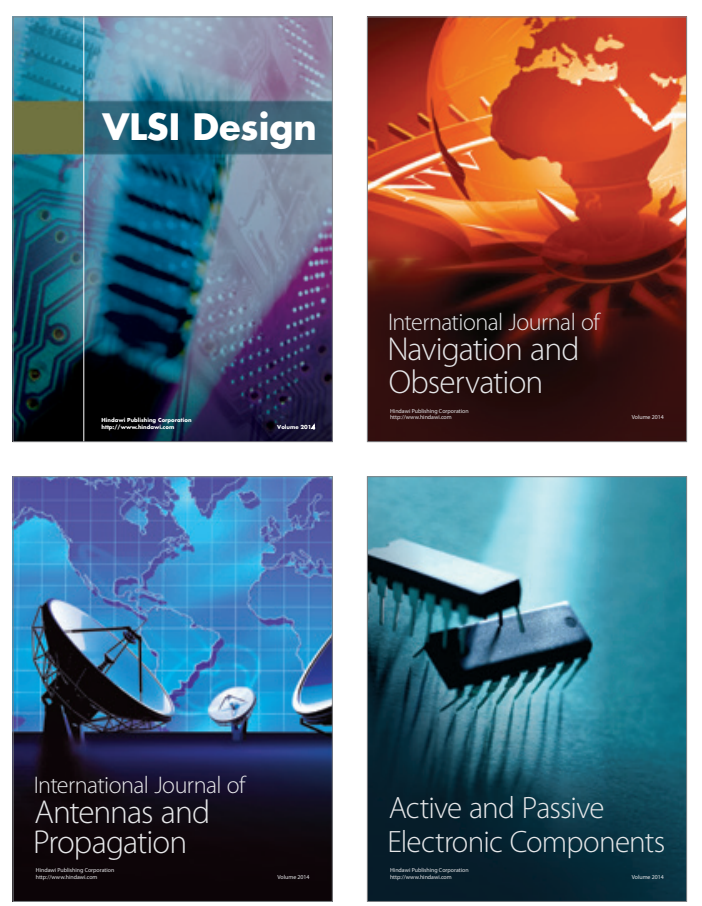
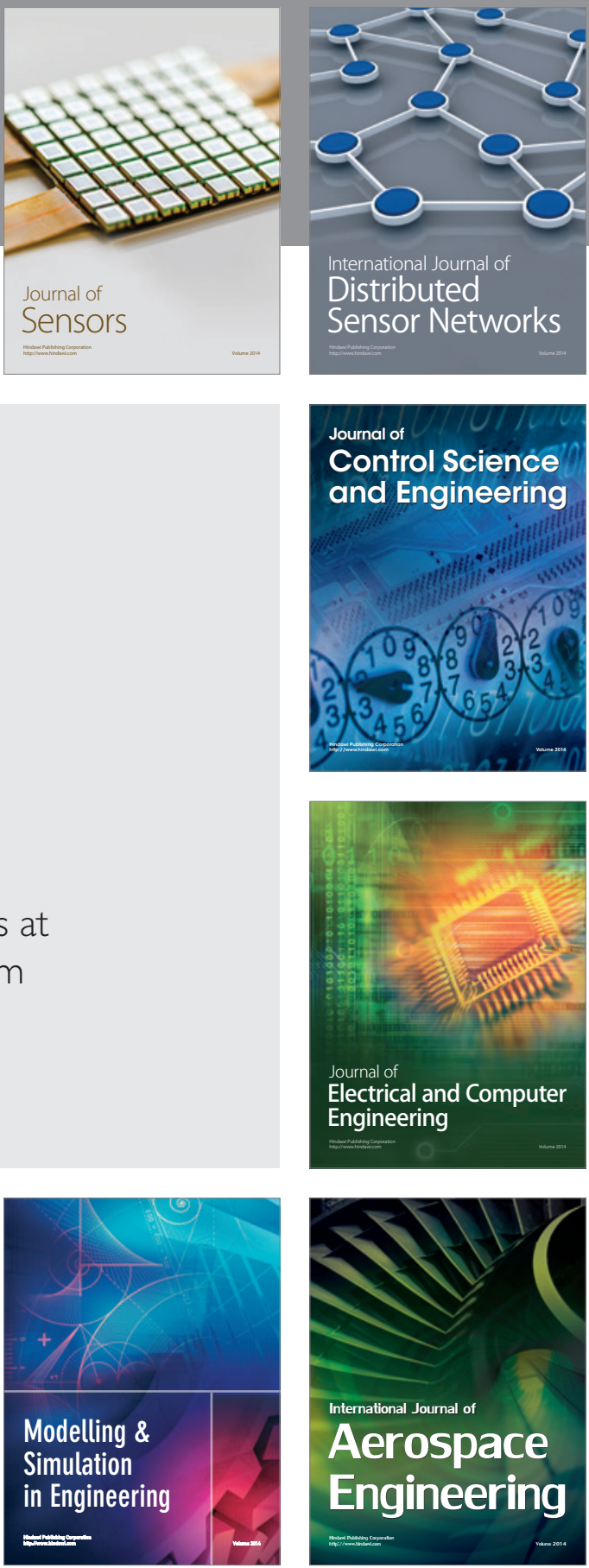

Journal of

Control Science

and Engineering
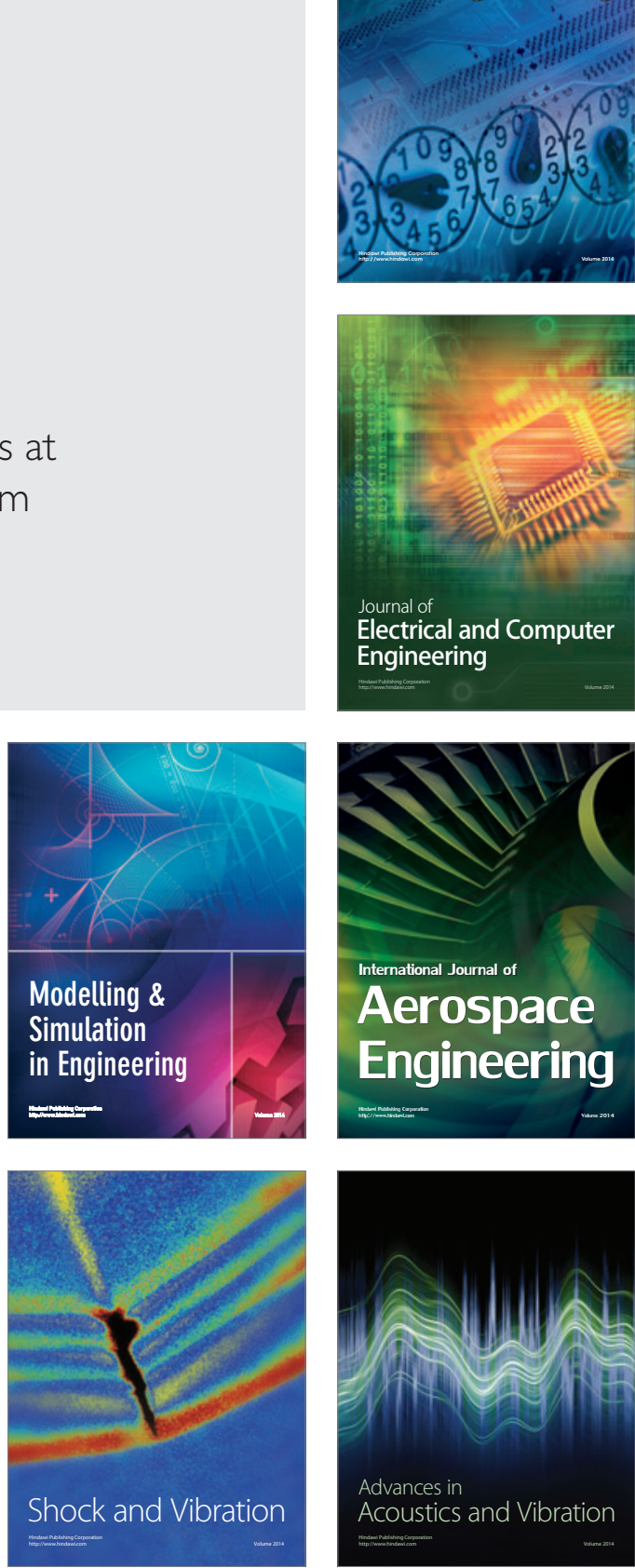